\title{
SEISMIC STABILITY ANALYSIS OF INCA EARTHEN WALLS
}

\author{
ARTURO TORRES $^{1 *}$, MARCIAL BLONDET ${ }^{2}$ AND SANDRA SANTA CRUZ ${ }^{2}$ \\ 1e-mail: arturo.torres@pucp.pe \\ ${ }^{2}$ Departamento de Ingeniería \\ Sección Ingeniería Civil, Pontificia Universidad Católica del Perú (PUCP) \\ Avenida Universitaria 1801, San Miguel 15088, Lima, Perú \\ email: \{mblondet, ssantacruz\}@ pucp.edu.pe,www.pucp.pe
}

Keywords: Inca walls, Rocking, Adobe, Tapial

\begin{abstract}
In many places around the world there still exist statues, walls and columns which, despite being located in areas of high seismicity, are still standing and in good conditions after several hundred years. Although Peru is located on a zone of high seismicity, some preColumbian walls are still standing after having withstood many intense earthquakes. The remarkably stable dynamic response of these structures when rocking freely due to horizontal ground motions has been extensively studied [1] [2]. The aim of the project presented in this article is to evaluate the probability of seismic overturning of Inca monuments (XVth century CE) during future strong earthquakes. The Wiracocha temple walls located near Cusco and the Inca trail walls that cross the PUCP campus in Lima were selected for this study. Both earthen walls were modelled as free-standing rigid blocks which could rotate around the corners at their base. A set of synthetic ground acceleration signals were then generated according to the seismicity and ground conditions of both sites. The artificial ground acceleration records were scaled to the uniform hazard spectrum of Peru for return periods of 500, 1000 and 2500 years and different moment magnitudes [3] [4]. The rocking time history response of each wall due to these ground motions was then numerically computed and plotted in order to assess the seismic risk due to overturning of these important earthen monuments.
\end{abstract}

The main conclusion is that these walls will most probably remain standing for many more centuries.

\section{INTRODUCTION}

In many areas of high seismicity across the world you can visit historical monuments that are simply supported and are still standing and in good condition many centuries after being built. In Peru, for example, some pre-Columbian walls have survived several intense earthquakes, while other similar structures have collapsed. This work aims to give some explanations for this phenomenon by analyzing the seismic rocking response of rigid blocks.

The rocking of rigid blocks subjected to horizontal base motions has been extensively studied ever since Housner published a seminal article on the topic [1]. Since then, many researchers have expanded significantly on the theory (see, for example, [2]) and developed analytical, numerical and experimental studies to better understand this interesting and 
complex phenomenon.

This article briefly presents the analytical formulation and a numerical method to estimate the rocking response of rectangular rigid walls caused by horizontal seismic excitation at the base. The mathematical expressions presented were then used to evaluate the seismic safety of two Peruvian pre-Hispanic monuments. For this study, a portion of the wall of the temple of the god Huiracocha in Raqchi, near Cusco, and a portion of the border wall of the Inca trail that crosses the PUCP campus (in Lima) were selected. Both earthen walls were built in the Inca period, during the 15 th century AD. Ground shaking was characterized by a set of synthetic horizontal acceleration signals, generated according to the local seismicity and soil conditions of both locations. For each site, synthetic accelerograms were generated corresponding to return periods of 500 years (rare earthquake), 1000 years (very rare earthquake) and 2500 years (extraordinary earthquake), and for moment magnitudes consistent with the local seismicity [3][4]. The time history rocking response of each wall was calculated numerically and then the overturning seismic risk of these important earthen monuments was then evaluated.

The main conclusion of the study is that the Inca wall at PUCP will probably collapse during a future earthquake, while the Huiracocha wall in Raqchi will remain standing for many more centuries.

\section{SEISMIC ANALYSIS OF RIGIID BLOCKS}

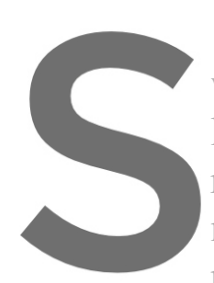

In 1963 Caltech pro

where he presented the

lower corners due to th

response of rigid solid

numerical and experim

parameters of the generic rigid block studied i
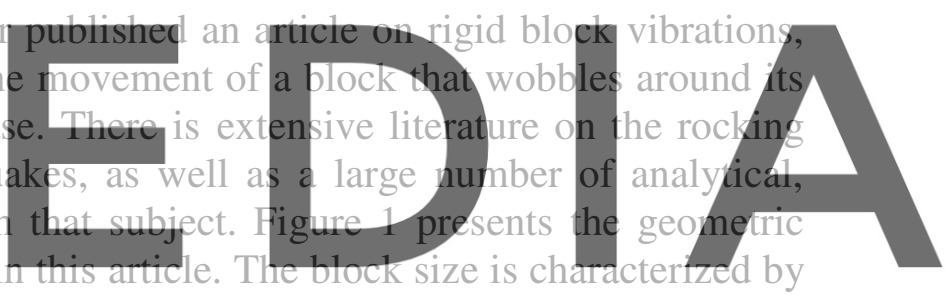

the radius $R$ and the slenderness is described by the characteristic angle $\alpha=\operatorname{atan}(\mathrm{b} / \mathrm{h})$. The

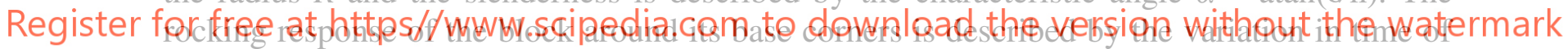
the rotation angle $\theta$.
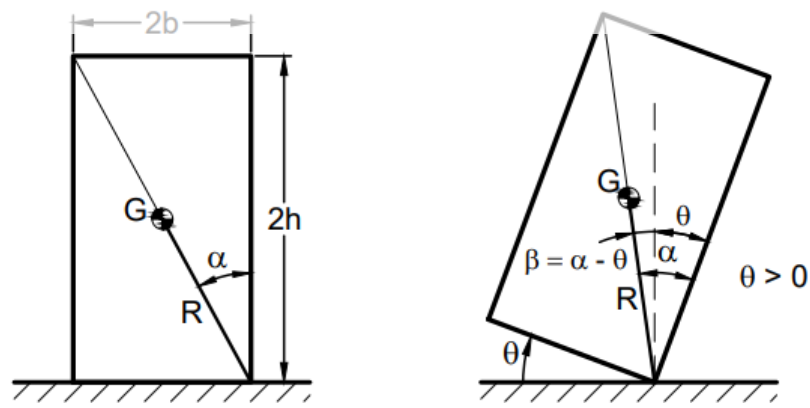

Figure 1 Geometric parameters of the rigid block

If a rigid block is subjected to an acceleration at its base $\ddot{u}_{g}(t)$, it will move together with the ground as long as $\ddot{u}_{g}<\mu g$ where $\mu$ is the coefficient of static friction between the block and the ground and $g$ is the acceleration of gravity.

The condition for no slip in the base is then 


$$
\left|\ddot{u}_{g}\right|<\mu g
$$

the block will not uplift as long as the moment of the inertia forces is less than the resistant moment due to the weight, that is if $m \ddot{u}_{g} h<m g b$. Therefore, the condition for the block to start rotating around a lower corner is

$$
\left|\ddot{u}_{g}\right| \geq g b / h
$$

\subsection{Rocking equation of motion}

The equations of motions developed by Housner (1963) are presented here. Rocking response of a rectangular block was expanded on and discussed in detail by Makris and Roussos (2000) [5]. It is assumed that the block is perfectly rigid and that impact with the ground is produced by a concentrated force acting in a lower corner. The rocking equations of motion are the following,

When the angle of rotation is positive,

$$
I_{0} \ddot{\theta}+m g R \operatorname{sen}(\alpha-\theta)=-m \ddot{u}_{g} R \cos (\alpha-\theta), \quad \theta>0
$$

Meanwhile, when the angle of rotation is negative,

$$
I_{0} \ddot{\theta}+m g R \operatorname{sen}(-\alpha-\theta)=-m \ddot{u}_{g} R \cos (-\alpha-\theta), \quad \theta<0
$$

For rectangular blocks, $I_{0}=(4 / 3) m R^{2}$, and the equations (3) are expressed as
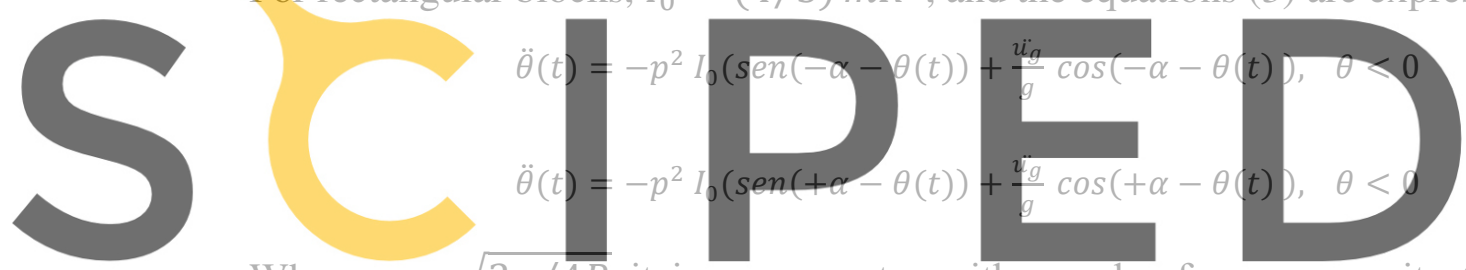

Where $p=\sqrt{3 g / 4 R}$ it is a parameter with angular frequency units (called "frequency

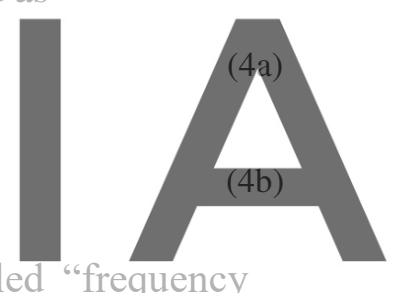

Register forameter" although it is not iropgrtional to the angylar naturil frequency without the watermark

The principte of conservation of angular momentum implies that the block loses energy

every time the pivot moves from one corner to the other at each swing. If the coefficient of restitution $\mathrm{r}$ is defined as the ratio between kinetic energies after and before impact, that is $\sqrt{r}=\frac{\dot{\theta}_{1}}{\dot{\theta}_{2}}$, the equation published by Makris and Zhang (2001) [2] is obtained:

$$
r=\left(1-\frac{3}{2} \operatorname{sen}^{2} \alpha\right)^{2}
$$

\subsection{Numerical integration methods}

A rigid block subjected to excitation at its base will begin to oscillate around a lower corner if $\ddot{u}_{g}>g b / h$ (equation 2) and, while the oscillations last, its movement will be governed by equations ( $3 a$ ) and (3b). There are several numerical methods to solve these equations and calculate the response of slender rigid blocks subjected to seismic excitation. This work uses the method presented by Santa Cruz (2000) [6], which is based on the method of interpolation of the excitation published by Chopra (2014) [7] to study the seismic response of viscoelastic oscillators. 
The acceleration of the ground $\ddot{u}(t)$ must be discretized at equal intervals of duration $\Delta \mathrm{t}$. If for the instant $t_{i}$, the angle of rotation $\theta_{i}$, the angular velocity $\dot{\theta}_{l}$ and angular acceleration $\ddot{\theta}_{l}$, are known, we want to calculate these values for the next instant $t_{i+1}=t_{i}+\Delta \mathrm{t}$.

The following expressions, in which $p t=p \Delta t$, sh $=\operatorname{senh} p t$, and $c h=\cosh p t$, are sufficient to calculate the rotation $\theta_{i+1}$ and angular velocity $\dot{\theta}_{i+1}$ at the end of the interval.

$$
\begin{gathered}
\theta_{i+1}=A \dot{\theta}_{l}+B \theta_{i}+C \ddot{u}_{i+1}+D \ddot{u}_{i}+K \\
\dot{\theta}_{i+1}=A^{\prime} \dot{\theta}_{l}+B^{\prime} \theta_{i}+C^{\prime} \ddot{u}_{i+1}+D^{\prime} \ddot{u}_{i}+K^{\prime}
\end{gathered}
$$

Where

$$
\begin{array}{cc}
A=s h / p & A^{\prime}=c h \\
B=c h & B^{\prime}=p \cdot s h \\
C=(1-s h / p t) / g & C^{\prime}=(1-c h) / g \Delta t \\
D=(\operatorname{sh} / p t-\operatorname{ch}) / g & D^{\prime}=(c h-p t \cdot \operatorname{sh}-1) /(g \Delta t) \\
K=\alpha(1-\operatorname{ch}) \operatorname{sgn}\left(\theta_{i}\right) & K^{\prime}=-\alpha p \cdot \operatorname{sh} \cdot \operatorname{sgn}\left(\theta_{i}\right)
\end{array}
$$

Finally, the angular acceleration of the block at the end of the interval $\ddot{\theta}_{i+1}$ is obtained from the equations of motion ( $3 a$ and $3 b$ ).

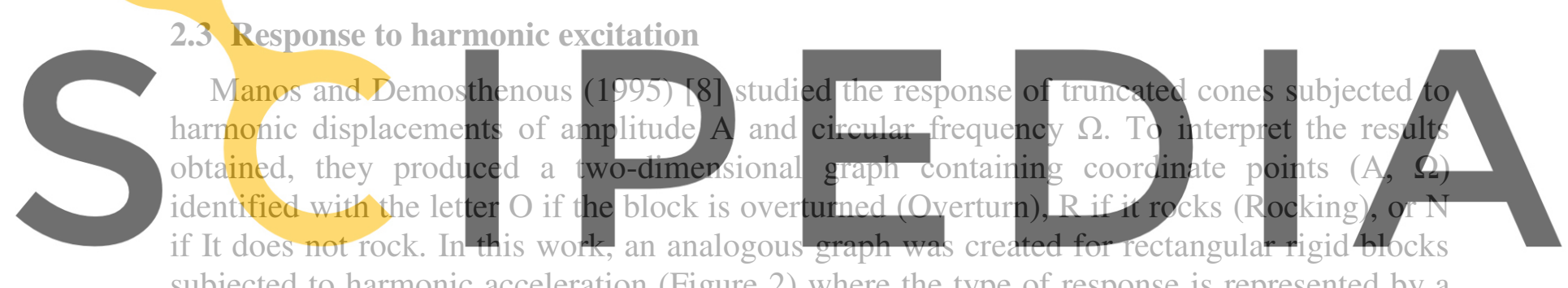
subjected to harmonic acceleration (Figure 2) where the type of response is represented by a

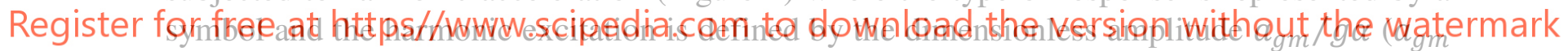
is the peak acceleration, $g$ is the acceleration of gravity and $\alpha$ is the characteristic angle of the block) and the frequency ratio $\omega_{g} / p$.

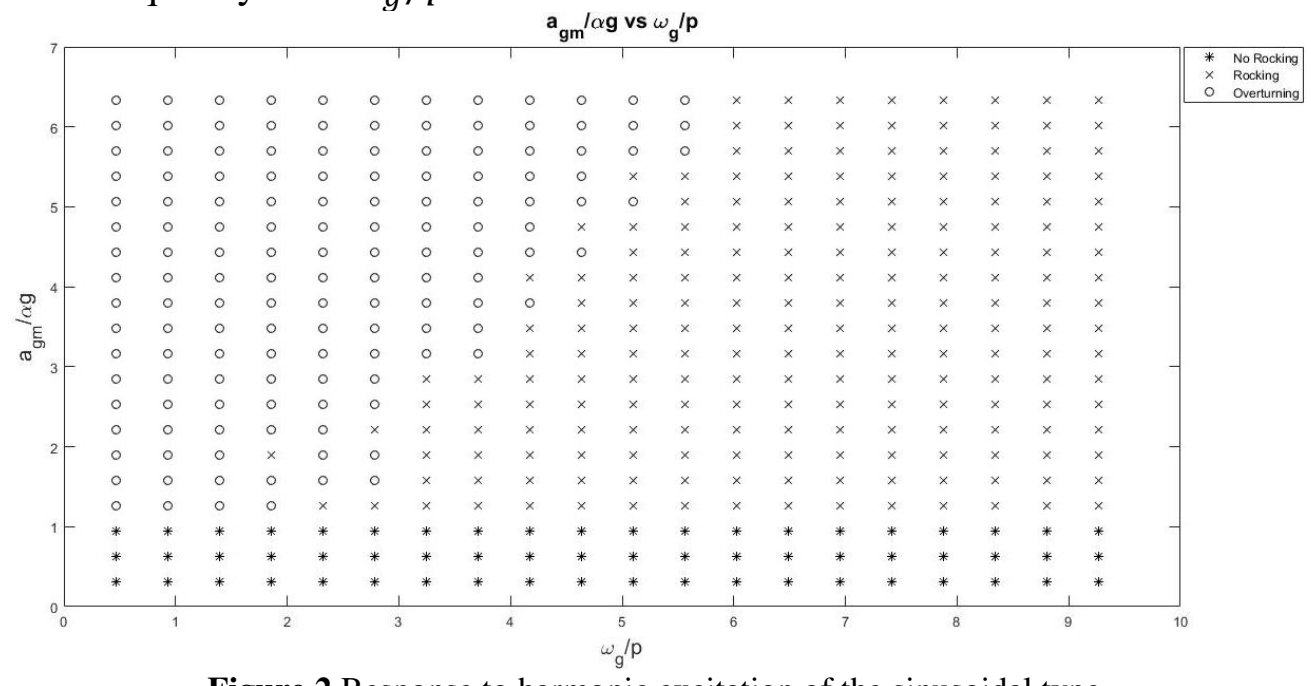

Figure 2 Response to harmonic excitation of the sinusoidal type 
It is observed that, in the entire frequency range studied, if the amplitude of the harmonic movement is small, the blocks translate with the ground and that there is a well defined amplitude of the ground motion from which the blocks oscillate. For low frequencies, the blocks overturn, while for high frequencies the blocks oscillate, and only overturn when the intensity of the movement increases. As the intensity of the base motion increases, the frequency zone in which the blocks are turned widens, but the threshold that defines whether a block turns over is not clearly defined.

In order to visualize the dynamic behavior of the block subjected to harmonic excitation as a function of time, a three-dimensional response spectrum was drawn up, in which the variation of the dimensionless rotation response amplitude $\theta(\mathrm{t}) / \alpha$ is plotted as a function of time (in absolute value) for a series of rigid blocks with different frequency ratios $\omega_{g} / p$. The intensity of the excitation is characterized by the dimensionless ratio PGA / $\mathrm{g} \tan \alpha$. To calculate the response of rotation of each block, the ground acceleration record was smoothed by means of a Blackman-Harris window [9] so that the movement of the soil begins and ends smoothly. The 3D response spectrum is then a surface on the plane $\omega_{g} / p$ vs time, whose height is the dimensionless rotation response $\theta / \alpha$.

Figure 3 shows the 3D spectrum corresponding to an intensity PGA / g tan $\alpha=4$. The amplitude of the rotation at each moment is measured by the height of the surface above the base plane $(\theta=0)$ and can be better visualized by the color, which varies from dark blue for small oscillations to yellow for large oscillations. The blocks are considered to overturn when

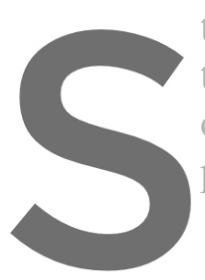
the inclination of the

then represents the rot collapse can be visualized as plane $\theta / \alpha=1$.
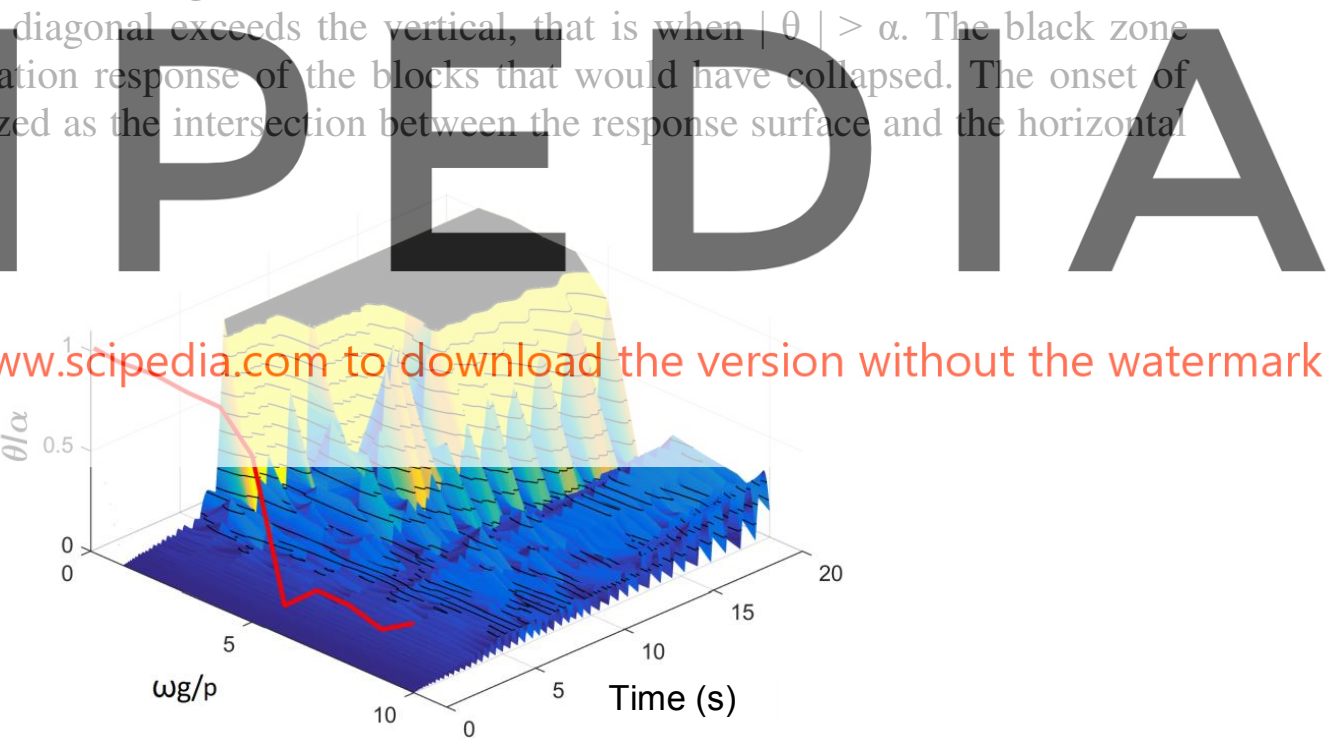

Figure 3 3D response spectrum of block rotation response to harmonic excitations

It is interesting to note that the projection of the $3 \mathrm{D}$ surfaces on the plane at $\mathrm{t}=0$ (the red line in Figure 3) represents the traditional 2D response spectrum, in which the maximum amplitude of the rotation response $\theta / \alpha$ is plotted versus the frequency ratio $\omega_{\mathrm{g}} / \mathrm{p}$.

To study the influence of the intensity of the harmonic excitation on the rigid block rotation response, the maximum rotation response for several intensity levels was calculated, and Figure 4 shows the results obtained. 


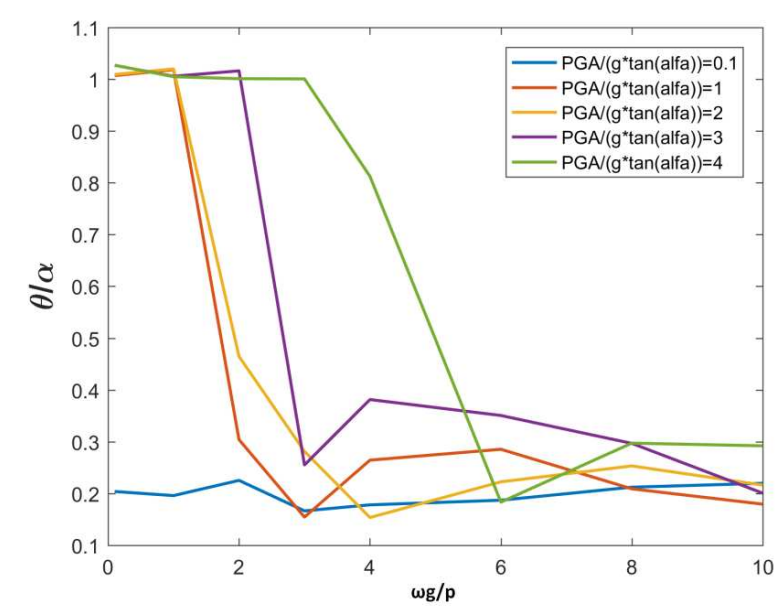

Figure 4 Block rotation response spectra for harmonic excitations

It is observed that for very low excitation levels (PGA $\leq 0.1 \mathrm{~g} \tan \alpha$ ), the rotational response is also low, with $\theta \max \approx 0.2 \alpha$ and no overturning. For high intensities (PGA $\geq \mathrm{g}$ tan $\alpha)$ and low frequencies some blocks tend to tip over a range of frequencies that increase as the intensity increases. A transition zone is noted between the overturning frequency range and the frequency range with low amplitude oscillations. Makris (2014) [10] and Bachmann et al. (2018) [11] also studied this phenomenon in great detail and produced graphs that show the complex relationship - between the rocking response and the intensity and frequency
characteristics of sinusoidal puises. The authors of this paper generated Figure 5, which shows a 2D graph of rotational amplitude $\theta / \alpha$ vs frequency intensity PGA / g tan $\alpha=5$, in which the overturning black zone $(\theta / \alpha=1)$ is con the Bachmann and Makris graphs.
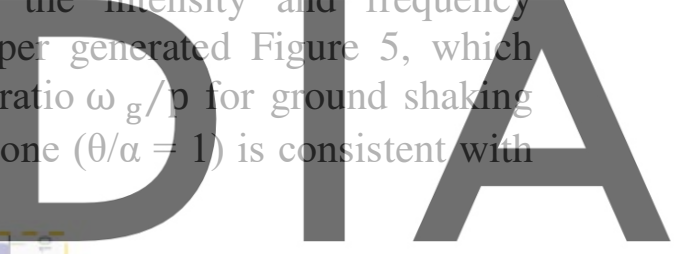

Register for free at https//www.scipedia.com to download the version without the watermark

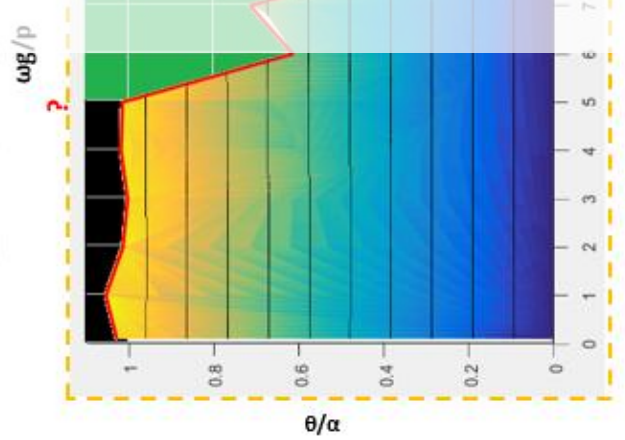

Figure 5 Rocking spectra

\section{SEISMIC ANALYSIS OF THE INCA WALLS}

The Huiracocha temple (Figure 6a) is located in the town of Raqchi, 118 kilometers from the city of Cusco. Legend says that Raqchi's citizens had stopped worshiping the god Huiracocha, and he, to punish them, sent a rain of fire. That is why after the punishment, the 
people of Raqchi built this temple for his worship. Since the walls of the Huiracocha temple are damaged, the residents of Raqchi have decided to reinforce them as shown in Figure 6a.

Some walls of the Inca Trail (Figure 6b) are located within the PUCP university campus in the city of Lima, on the central coast of Peru. The Inca Trail (Qhapaq Nan) is a walled road that in ancient times connected important sites of the Inca empire. Many sections of the trail were destroyed for the construction of the University Avenue road in Lima. The 467 meters of the Inca Trail that are inside the PUCP campus are conserved with great care by the university community.
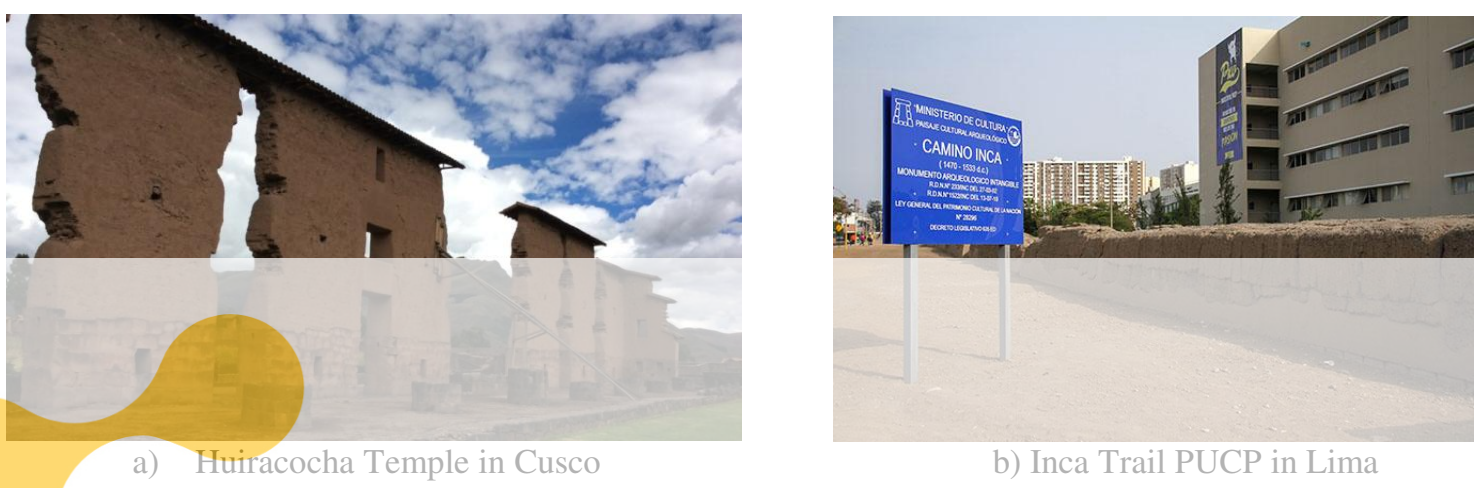

b) Inca Trail PUCP in Lima

Figure 6 pre-Hispanic earthen walls studied

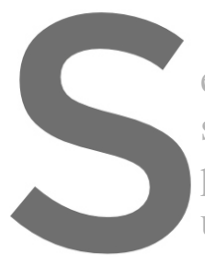

The risk of seismic evaluated by analyzing
shaking was specified v
periods of 500,1000 and
uniform density subjecte
each wall were measured $2500 y$
their
ia synth
d only to ning of the Hui
rocking respon
hetic accelerog
years. Each wal
to horizontal seis iracocha Temple
ise to simulated
was modelled as a
ismic excitation e and the Inca
d earthqyake
ding to earthqu
as a rigid rect:
at the base. T Trail
motion
The dim

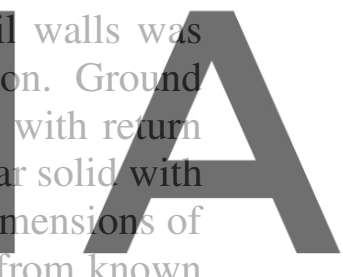

to the ground motions earthquakes generated for each site was calculated. Finally, the seismic risk of each wall was characterized by the period of return of the earthquake capable of producing wall failure due to overturning.

To assess the vulnerability of historical monuments, it is necessary to estimate with confidence the seismic hazard of the region where they are located, for which it is required to have a large database of seismic records over time. In Peru, unfortunately, these records are still scarce and the use of synthetic accelerograms is required to perform seismic risk studies of important buildings such as historical monuments.

Synthetic signals appropriate to the sites studied were generated as follows: first, the distance to the nearest seismogenic source and the soil stiffness characteristics of each site were estimated. With this information, uniform hazard spectra were generated, and scaled to the spectral form of document FEMA 356 [12]. Finally, appropriate attenuation curves were applied in order to obtain acceleration spectra corresponding to earthquakes with return periods of 500 years (rare earthquakes), 1000 years (very rare earthquakes) and 2500 years (extraordinary earthquakes), respectively.

Peru is located in an area of high seismic activity due to the subduction process of the 
Nazca plate below the South American plate. Figure 7 [3] shows the seismogenic sources corresponding to the capital city of Lima and the imperial city of Cusco. To generate the synthetic accelerograms used in this study for each of these cities, it was decided to use the SeismoArtif 2018 software.

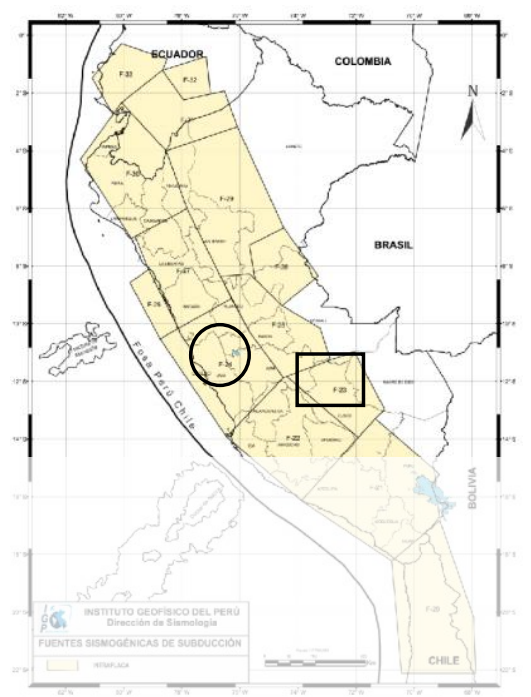

Figure 7 Map of seismogenic foci of Peru and location of Lima and Cusco

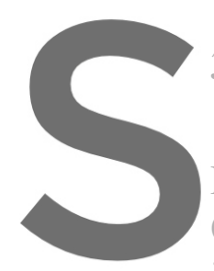

\subsection{Accelerograms \\ The seismogenic \\ Figure 7) and geometric \\ Only the F-23 source w
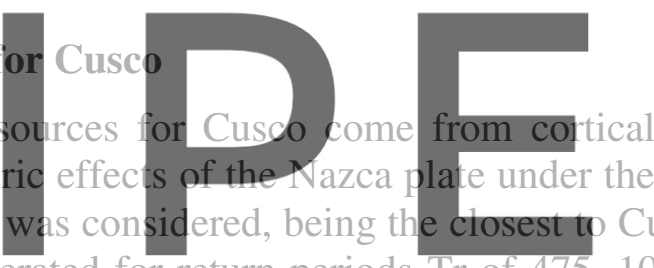

in Figure 8 were generated for return periods 1
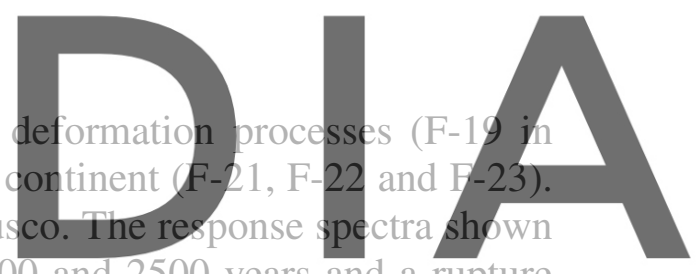

Tr of 475, 1000 and 2500 years and a rupture

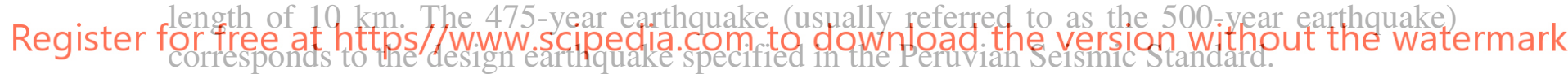

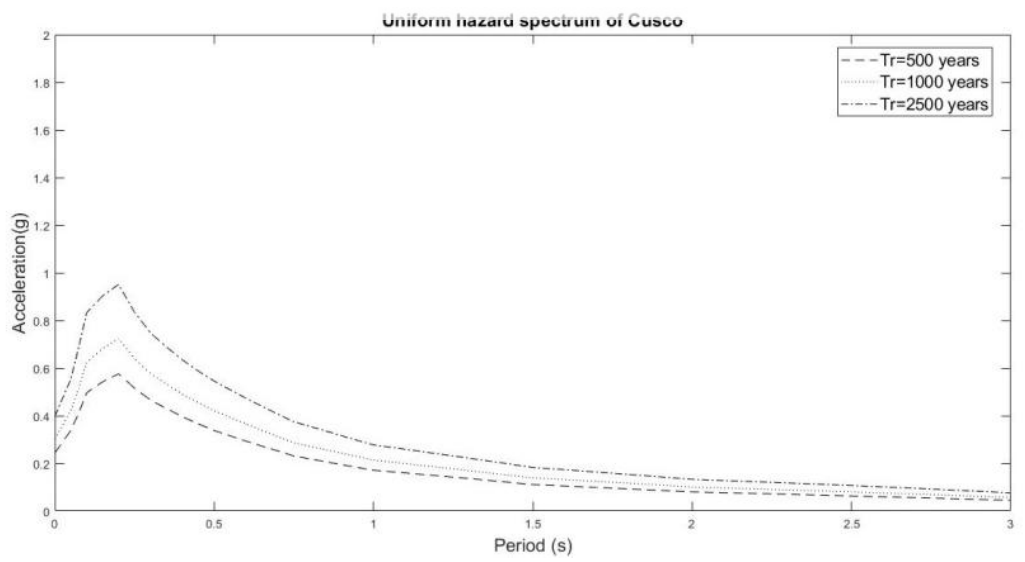

Figure 8 Spectra of synthetic earthquakes generated for Cusco

Figure 9 shows a set of synthetic accelerograms for the city of Cusco, compatible with the generated spectra. 


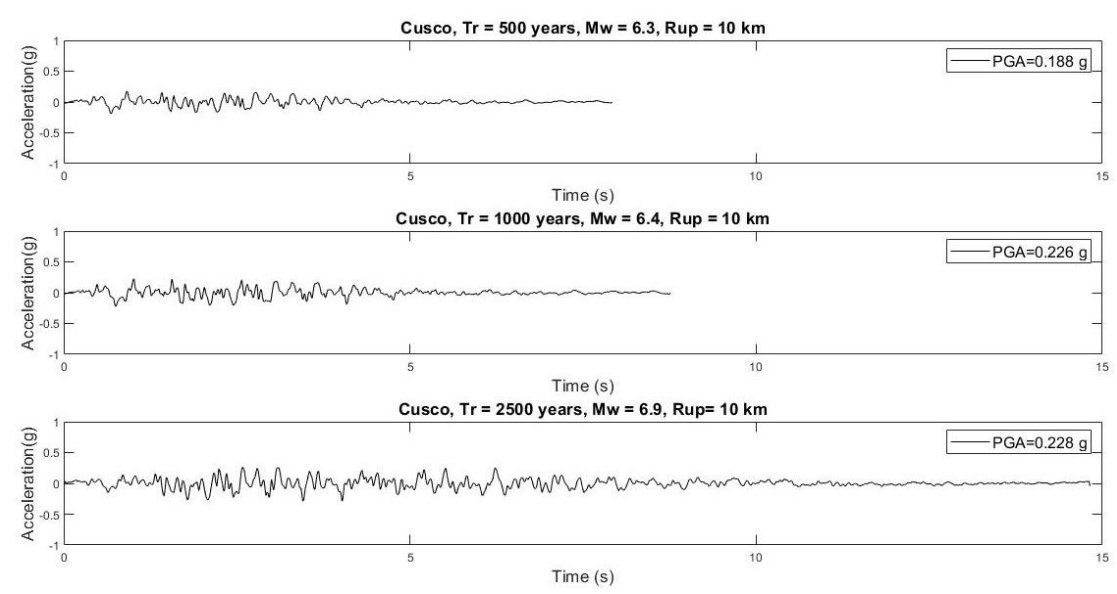

Figure 9 Synthetic accelerograms for Cusco

\subsection{Accelerograms for Lima}

The seismogenic sources for Lima shown in Figure 7 come from subduction (F-24) and interface (F-4) processes. Only the F-24 source was considered, as being the closest to Lima, with a rupture length of $25 \mathrm{~km}$. The spectra generated for Lima appear in Figure 10 and a compatible set of accelerograms is shown in Figure 11.
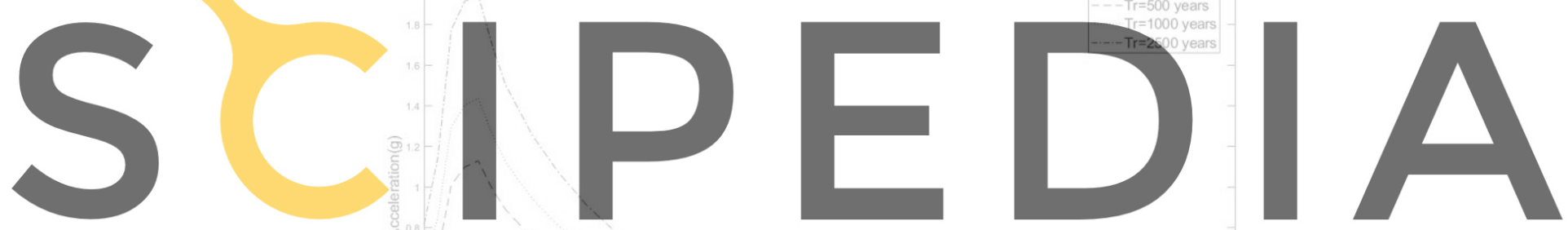

Register for free at https//www.scipedia.com to download the version without the watermark

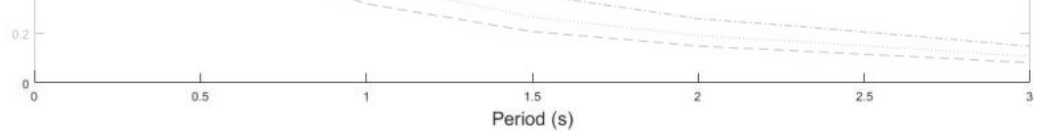

Figure 10 FEMA 356 Design Spectrum for $\operatorname{Tr}=475$ years, 1000 and 2500 years, (Barreto 2019)
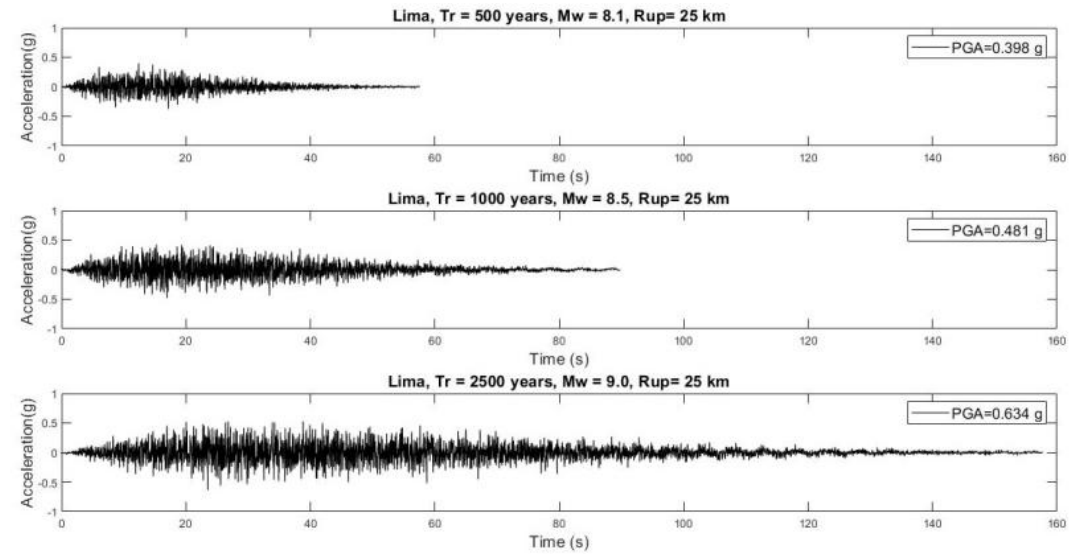

Figure 11 Synthetic accelerograms for Lima 


\subsection{Seismic analysis of the Huiracocha temple}

The wall is composed of a stone base of total height $H_{P}=3 \mathrm{~m}$ and mass $m_{P}=57,700 \mathrm{~kg}$, on which an adobe wall of height $H_{A}=9 \mathrm{~m}$ and mass $m_{A}=106,500 \mathrm{~kg}$ rests. The average wall thickness is $1.5 \mathrm{~m}$ and the average width is $5 \mathrm{~m}$. The average density of the stone wall was considered to be $2600 \mathrm{~kg} / \mathrm{m}^{3}$ and the average density of the adobe wall is $1600 \mathrm{~kg} / \mathrm{m}^{3}$.

To perform the seismic analysis, the wall was modeled as a rigid rectangular solid of uniform material, with total mass $m=m_{A}+m_{P}=164,200 \mathrm{~kg}$, total height $2 \mathrm{~h}=11.42 \mathrm{~m}$ and base $2 b=1.50 \mathrm{~m}$, so that the mathematical model has the same moment of rotational inertia $I_{o}=7.0 \times 10^{6}$ as the real wall. Figure 12 shows a photo of the wall and a drawing of the mathematical model used in seismic analysis.

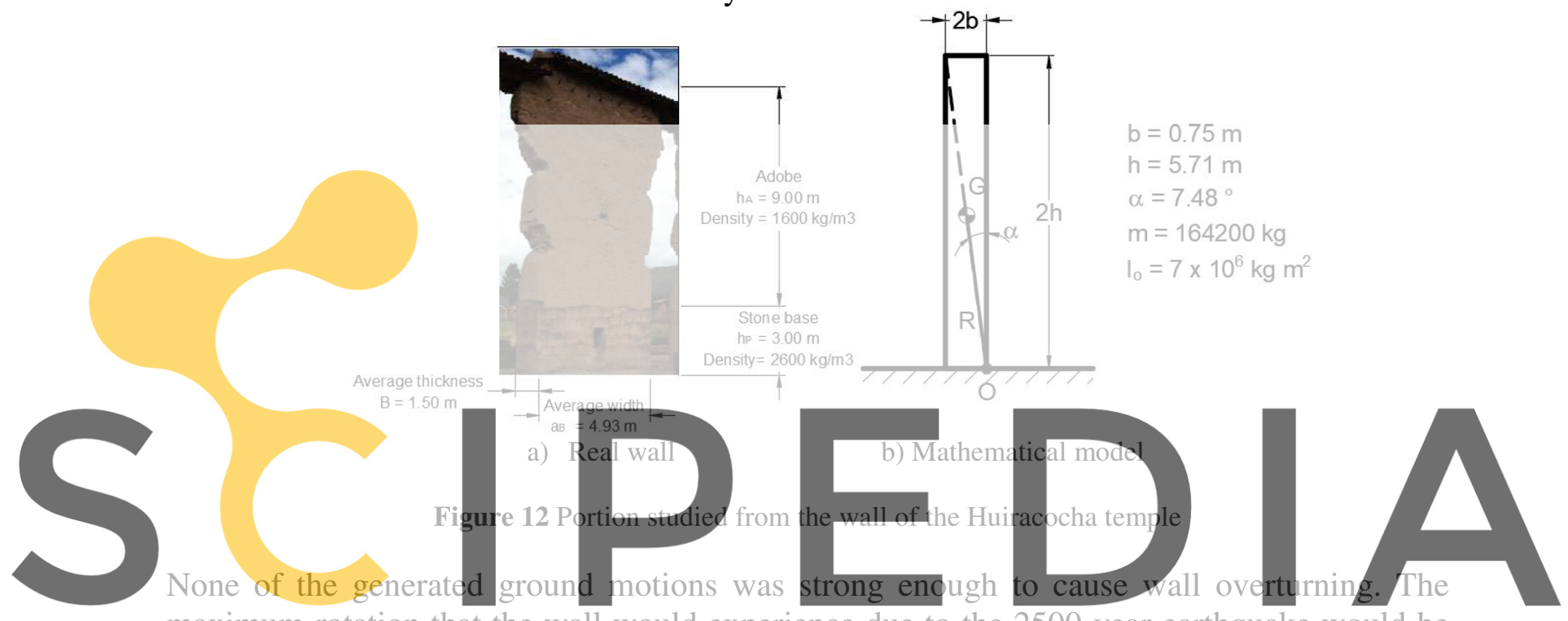

maximum rotation that the wall would experience due to the 2500-year earthquake would be

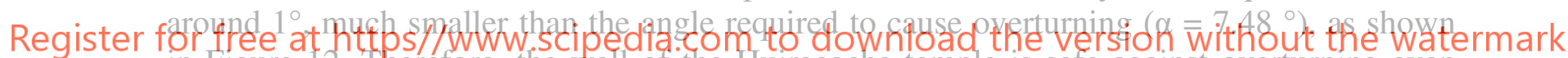
in Figure 12. Therefore, the wall of the Huiracocha temple is safe against overturning even

with the most intense earthquake possible in Raqchi.
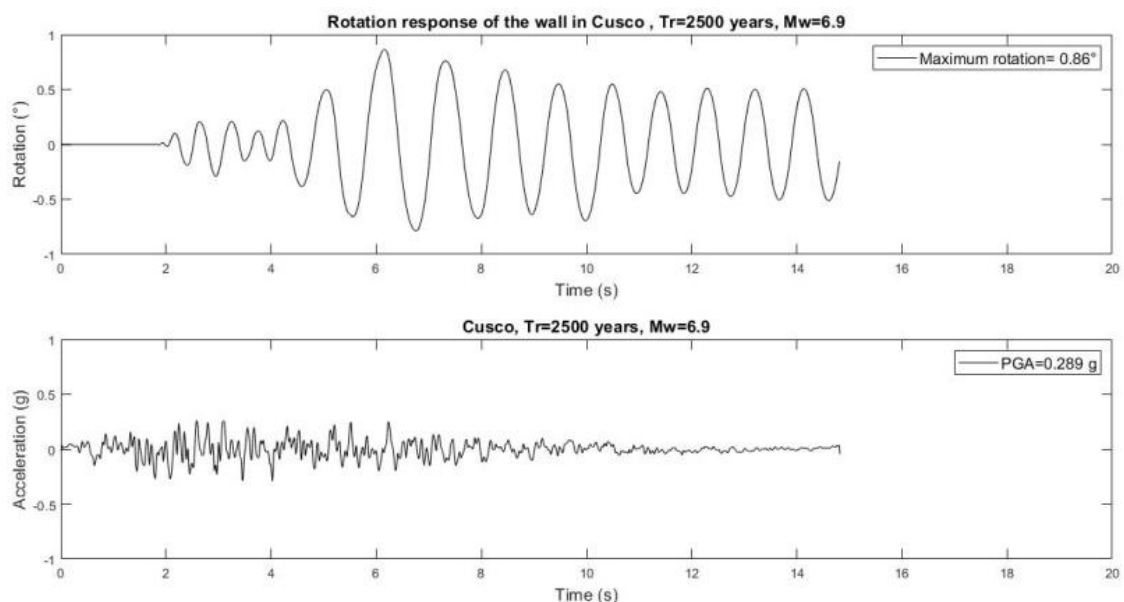

Figure 13 Rotation response of the Huiracocha temple wall for a synthetic signal of $\operatorname{Tr}=2500$ years and $\mathrm{Mw}=6.9$ 


\subsection{Seismic analysis of the PUCP Inca Trail in Lima}

The out-of-plane seismic response of the wall portion shown in Figure 14a was studied. The wall is made of tapial and has a total height $2 h$ of $2.80 \mathrm{~m}$ and a total mass $m$ of approximately $10,800 \mathrm{~kg}$. The average wall thickness is $0.55 \mathrm{~m}$ and the average width is 4.40 $\mathrm{m}$. The average density of the material was considered to be $1,600 \mathrm{~kg} / \mathrm{m}^{3}$.

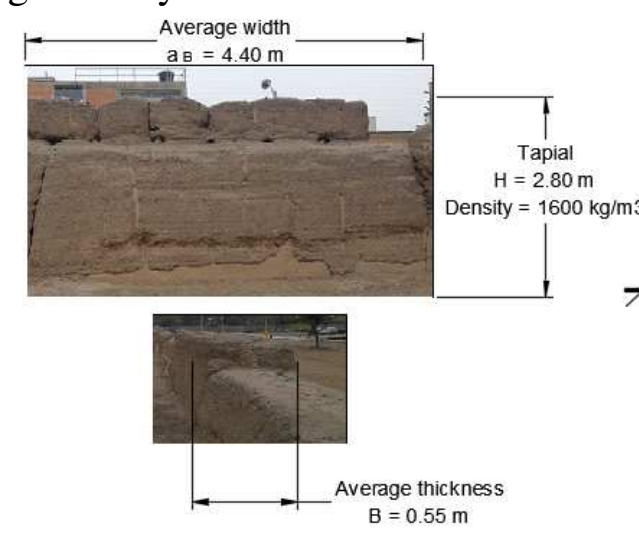

a) Real wall

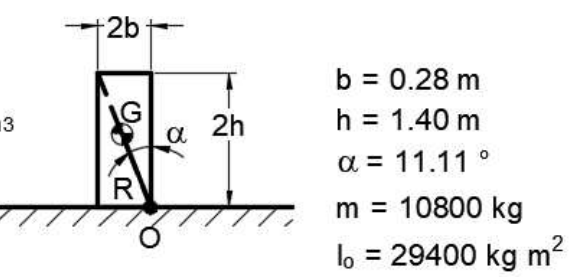

b) Mathematical model

Figure 14 Portion studied of the wall

Dynamic analysis of the wall reveals that this wall would rock without overturning during the 500-year earthquake, but that it would overturn due to the 1000-year earthquake, as shown in Figure 15.
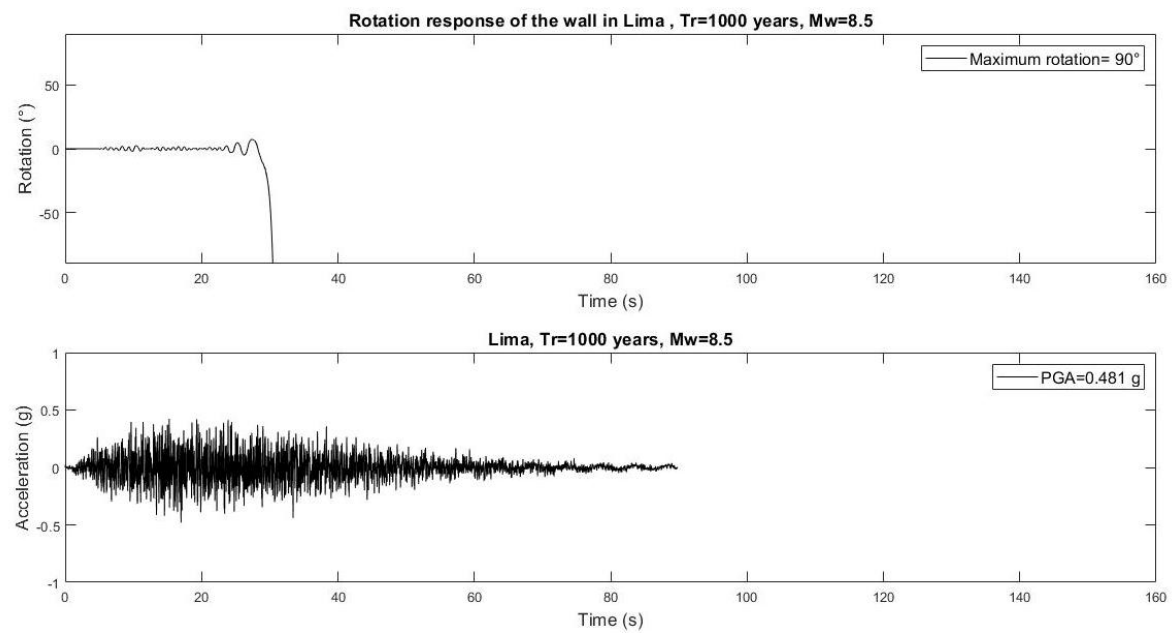

Figure 15 Response of the PUCP Inca Trail wall to a synthetic ground motion with $\operatorname{Tr}=1000$ years and $\mathrm{Mw}=8.5$

\section{CONCLUSIONS}

In several highly seismic areas of the world there are independent, simply supported historical monuments that have survived intact for many centuries, while nearby buildings have collapsed. This information is surprising and motivating to study the seismic response of rigid solids that respond by rocking under base movements.

Although the oscillating movement of rigid blocks subjected to excitation at the base is 
complex, it is possible to develop reasonable equations of motion assuming perfectly elastic impact forces concentrated in the corners. These equations can be solved numerically with acceptable precision by methods widely available in the literature. In particular, the method of excitation interpolation has yielded seemingly reliable results to study the response of the preHispanic walls of Raqchi and the Inca Trail.

The 3D response spectra allow visualization of the evolution of the dynamic response of rigid blocks with different physical characteristics subjected to harmonic excitation in the base, and seem useful to describe the complex phenomenon of the rocking response of structures that can be modeled as rigid blocks.

The return period of the earthquakes that would cause the walls to overturn is a useful piece of information to make decisions on the seismic protection for these valuable structures. For example, consideration should be given to adopting measures to improve the seismic protection of the walls of the Inca Trail. The methodology used in this work could be extended to evaluate a greater number of monuments and thus contribute to the improvement of the conservation and protection policies of historical monuments in seismic areas of the world.

\section{REFERENCES}

[1] Housner, G. W. (1963). The behavior of inverted pendulum structures during earthquakes. Bulletin of the Seismological Society of America, 53:2, 403-417.

[2] Zhang, J., \& Makris, N. (2001). Rocking Response of Free-Standing Blocks Under Cycloidal Pulses. Journal of Engineering Mechanics, 127(May), 473-483.

[3] Tavera, H. (2014). Re-evaluación del peligro sísmico probabilístico para el Perú, IGP.

[4] Roncal, M. (2017). Determinación del peligro sísmico en el territorio nacional y elaboración de aplicativo web.

[5] Makris, N., \& Roussos, Y. S. (2000). Rocking response of rigid blocks under near-source ground motions. Geotechnique, 50:3, 243-262.

[6] Santa Cruz,S.,Ordaze,M.,Guerrero del Ángel,R. (2017). Estimación de pérdidas en contenidos ubicados dentro de naves industriales debido a sismos. Sociedad Mexicana de Ingeniería Estructural.

[7] Chopra, A. (2014). Dinámica de Estructuras. Pearson Educación de México.

[8] Manos, G. C., \& Demosthenous, M. (1995). Models of Ancient Columns and Colonnades Subjected to Horizontal Base Motions-Study of their Dynamic and Earthquake Behaviour. Transactions on the Built Environment, 8, 1-3.

[9] Harris, F. (1978). On the use of Windows for Harmonic Analysis with the Discrete Fourier Transform.

[10] Makris, N. (2014). A half-century of rocking isolation. Earthquake and Structures, 7:6, 1187-1221.

[11] Bachmann, J. A., Strand, M., Vassiliou, M. F., Broccardo, M., \& Stojadinović, B. (2018). Is rocking motion predictable? Earthquake Engineering and Structural Dynamics, 47:2, 535-552.

[12] Federal Emergency Management Agency (FEMA), \& (ASCE), A. S. of C. E. (2000). Prestandard and commentary for the seismic rehabilitation of buildings. Federal Emergency Management Agency. 